\title{
The newly discovered ClpK protein strongly promotes survival of Klebsiella pneumoniae biofilm subjected to heat shock
}

\begin{abstract}
Klebsiella pneumoniae is an important nosocomial pathogen causing urinary tract, respiratory and blood infections (Podschun \& Ullmann, 1998).

Immunocompromised individuals such as

et al., 2010) and endoscope-mediated transmission of a carbapenem-resistant isolate belonging to the internationally successful K. pneumoniae clone ST258 (Naas et al., 2010).
\end{abstract} intensive care unit (ICU) patients and people suffering from severe underlying diseases are frequently susceptible to infection (Sahly et al., 2000). Thus, it is estimated that K. pneumoniae is second only to Escherichia coli as a cause of Gramnegative nosocomial sepsis (Sahly \& Podschun, 1997), and regarding bacteraemic cases within ICUs

K. pneumoniae has been identified as the most common Gram-negative agent in recent studies (Ben Jaballah et al., 2007; Couto et al., 2007; Michalopoulos et al., 2011). As a ubiquitous organism,

$K$. pneumoniae is a normal resident of the human gastrointestinal tract and nosocomial transmission from this reservoir is considered to occur mainly by personal contact and through inappropriately decontaminated hospital equipment (Montgomerie, 1979).

In hospitals, and in ICUs in particular, diagnostic and medical treatment procedures involving endoscopes require strict infection control measures since these devices are subject to repeated contact with mucosal surfaces of the patients. Reusable flexible endoscopes cannot be steam sterilized due to their material composition, and are generally reprocessed by cleaning, high-level disinfection and drying. High-level disinfection is often accomplished by a thermochemical treatment below $60{ }^{\circ} \mathrm{C}$ in washer-disinfectors. Reports of transmission and outbreaks of infectious agents being linked to endoscopes are numerous; e.g. K. pneumoniae outbreak due to an infected bronchoscope (Cetre et al., 2003), outbreak of multidrugresistant (extended-spectrum $\beta$-lactamase) $K$. pneumoniae linked to a duodenal scope used for endoscopic retrograde cholangiopancreatography (Aumeran
Bacterial biofilms are typically quite resistant to adverse environmental conditions imposing chemical and physical stresses (Costerton et al., 1987). Studies have shown that patient-ready endoscopes may be persistently contaminated despite adherence to recommended decontamination procedures (Bisset et al., 2006) and confirm the presence of bacterial biofilm on endoscopes by scanning electron microscopy (Pajkos et al., 2004), suggesting biofilm formation as a contributor to failure of pathogen elimination from scopes. We recently reported on an endemic $K$. pneumoniae strain (C132-98) persisting at an ICU which was eliminated concomitantly with an increased focus on endoscope reprocessing procedures. A pronounced heat resistance phenotype of planktonic cultures of C132-98, which was suggested to facilitate its nosocomial persistence, was shown to be mediated by a plasmidencoded heat resistance locus encompassing a gene encoding a novel ClpK protein (Bojer et al., 2010). Approximately $1 / 3$ of a collection of nosocomial K. pneumoniae isolates tested positive for the $c l p K$ gene and a correlation to a heat resistance phenotype of these isolates was established (Bojer et al., 2010). Since it is known that $K$. pneumoniae biofilm cells can be more resistant to ethanol disinfection (Chambers et al., 2006) as well as heat inactivation and some disinfectants (Faille et al., 2003;

LeChevallier et al., 1988), we sought to assess a possible clinical significance of this heat resistance locus by determining whether ClpK confers thermoprotection of K. pneumoniae biofilm-stage cells.

Determination of viability pre- and postheat shock was performed and compared in biofilm cells of wild-type (WT)

K. pneumoniae C132-98 and its isogenic

$\Delta c l p K$ deletion mutant and $\Delta c l p K$ mutant cells complemented by $c l p K$ (pClpK) or the complete heat resistance locus encompassing clpK (pMB58-sub) constructed previously (Bojer et al., 2010). In essence, individual biofilms were allowed to develop on Lab-Tek Permanox Chamber Slides (Nunc) for $48 \mathrm{~h}$ by $1 / 100$ dilution of overnight cultures in M9 medium (Sigma) supplemented with $0.02 \mathrm{M}$ glucose $/ 0.002 \mathrm{M} \mathrm{MgSO}_{4}$ and incubation at $37^{\circ} \mathrm{C}$ and 150 r.p.m. Planktonic and loosely adherent cells were removed by washing cover slides three times in PBS after which cover slides were placed in $50 \mathrm{ml}$ PBS in plastic tubes. Tubes for heat shock were pre-heated and maintained at $58{ }^{\circ} \mathrm{C}$ for $5 \mathrm{~min}$ followed by cooling in an ice-water bath. Untreated and heat-shocked biofilms were displaced from cover slides by addition of $0.1 \%$ Triton X-100 and applying two rounds of $10 \mathrm{~min}$ in a Bransonic ultrasonic cleaner (B-2200) separated by vigorous vortexing, and quantified as c.f.u. $\mathrm{cm}^{-2}$ by plating. Survival rates based on three independent experiments were analysed (1-way ANOVA; GraphPad Prism) following log-transformation of data to normalize the variance. Biofilm removal from cover slides was assessed qualitatively by traditional crystal violet staining.

Quantification of bacterial biofilms showed that $K$. pneumoniae C132-98 produces an extensive biofilm $\left(\sim 1.5 \times 10^{7}\right.$ c.f.u. $\mathrm{cm}^{-2}$ ). Also, the $c l p K$ deletion mutant and its complementation derivatives showed comparable amounts of biofilm (Fig. 1b). However, the survival rate following heat shock was strongly influenced by ClpK. While WT C132-98 biofilm remained practically unaffected ( $\sim 70 \%$ survival) by heat shock at $58{ }^{\circ} \mathrm{C}$ for $5 \mathrm{~min}$, the C132-98 $\Delta$ clpK mutant biofilm was significantly impaired $(\sim 0.02 \%$ survival) (Fig. 1c). The observed $>1000$ fold reduction in heat resistance of mutant 
cells was restored by complementation. Full complementation necessitates complementation with adjacently located genes (pMB58-sub) suggesting a polar effect from $c l p K$ deletion as indicated for planktonically grown cells also (Bojer et al., 2010). The relevance of the $c l p K$ gene alone in the heat resistance of $K$. pneumoniae biofilm is, however, evident from the significant protection $(>100$-fold improved survival) provided by $\mathrm{pClpK}$ (Fig. 1c).

Since biofilms are considered to constitute a significant proportion of the bacterial biomass clinically as well as environmentally, assessment of bacterial physiological responses should include biofilm-embedded cells. The sessile cells of bacterial biofilms are by definition physically different in organization to their planktonic counterparts and are also considered to be physiologically distinct (Donlan \& Costerton, 2002). Indeed, we observed that K. pneumoniae C132-98 biofilm cells remained viable in greater proportions than planktonic cells; i.e. the c.f.u. of planktonic cultures were generally reduced to approximately $20 \%$ following heat shock at $58{ }^{\circ} \mathrm{C}$ for $5 \mathrm{~min}$ (compared to the $\sim 70 \%$ survival of biofilm-embedded cells reported herein). Even at $60{ }^{\circ} \mathrm{C}$ heat shock, biofilm cells were only reduced approximately twofold in viability after 5 min whereas planktonic cells were practically eliminated. Thus, any effect by the ClpK heat resistance determinant might be masked by an intrinsic resistance of K. pneumoniae biofilm. This report does, however, show that ClpK significantly contributes to the survival of heat-shocked biofilm. The repeated reprocessing of medical devices may lead to build-up of resistant biofilms (Alfa \& Howie, 2009) and endoscopic procedures can be independent risk factors for acquisition of nosocomial pneumonia and bloodstream infections (Mastropierro et al., 2009; von Baum et al., 2005). Also, reprocessing temperatures in endoscope washer-disinfectors have been shown to be critical for minimizing the microbial load (Zühlsdorf et al., 2003). Altogether, the strong thermoprotection provided by ClpK may play a role in nosocomial persistence of certain $K$. pneumoniae strains. Elimination of K. pneumoniae C132-98 did coincide with increased focus on reprocessing procedures supporting this hypothesis. The possible clinical significance of this notion is underlined by a recent report on a multi-hospital outbreak of KPC-2-producing ST258 K. pneumoniae partially explained by endoscope transmission (Carbonne et al., 2010) as well as the aforementioned cases of nosocomial infection and transmission being linked to contaminated endoscopes.

\section{Martin S. Bojer, ${ }^{1,2}$ Karen A. Krogfelt ${ }^{1}$ and Carsten Struve ${ }^{1}$}

${ }^{1}$ Department of Microbiological Surveillance and Research, Statens

(a)

\section{Heat resistance locus from K. pneumoniae C132-98}

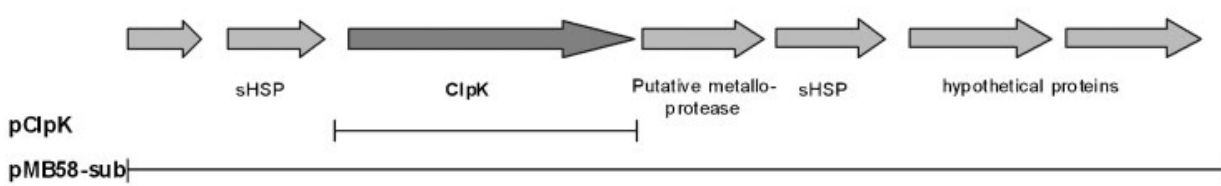

(b)

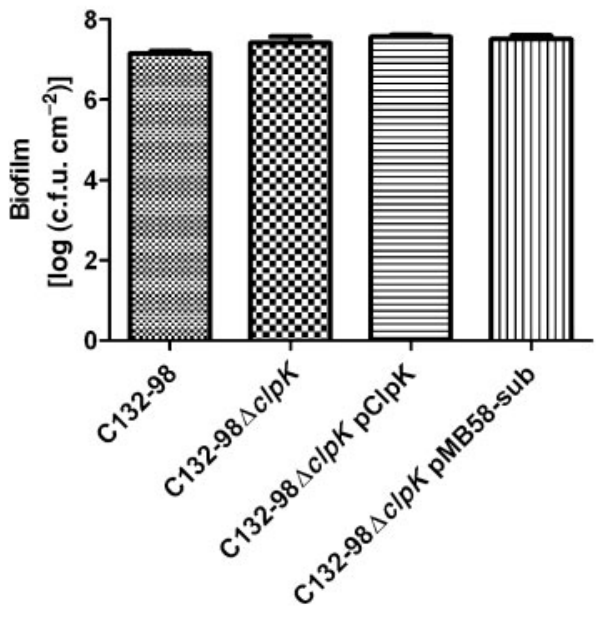

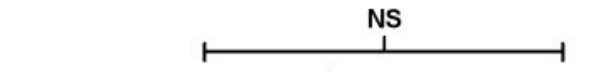

(c)

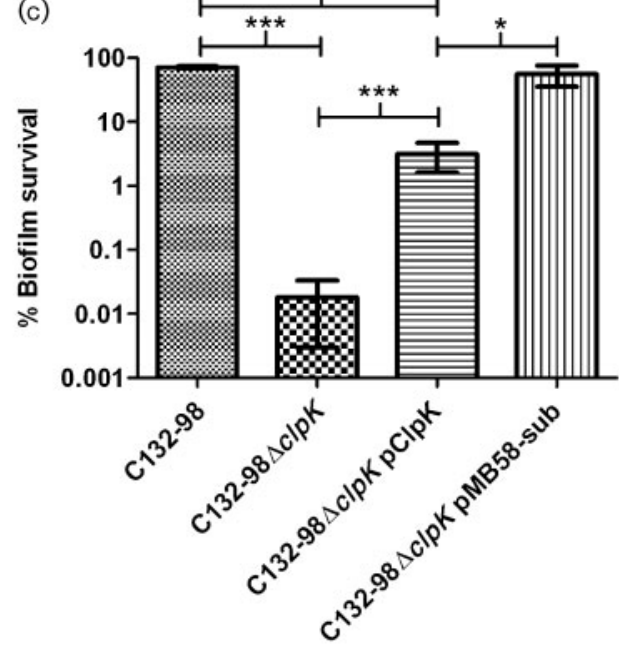

Fig. 1. (a) Plasmid-encoded heat resistance locus in K. pneumoniae C132-98 and subcloned (pACYC184) fragments covered by $\mathrm{pClpK}$ and pMB58-sub. (b) Amount of biofilm formed by WT C132-98, its isogenic $\Delta c / p K$ mutant, and the C132-98 $\Delta c / p K$ mutant complemented by either pClpK or pMB58-sub. (c) Survival of biofilm cells following 5 min of heat shock at $58{ }^{\circ} \mathrm{C}$ (NS, no significant difference; ${ }^{\star} P<0.05 ;{ }^{* \star \star} P<0.001$ ). 
Serum Institut, 2300 Copenhagen S, Denmark

${ }^{2}$ Department of Science, Systems and Models, Roskilde University, 4000 Roskilde, Denmark

Correspondence: Carsten Struve (cas@ssi.dk)

Alfa, M. J. \& Howie, R. (2009). Modeling microbial survival in buildup biofilm for complex medical devices. BMC Infect Dis 9, 56.

Aumeran, C., Poincloux, L., Souweine, B., Robin, F., Laurichesse, H., Baud, $O$., Bommelaer, G. \& Traoré, O. (2010). Multidrugresistant Klebsiella pneumoniae outbreak after endoscopic retrograde cholangiopancreatography. Endoscopy 42, 895-899.

Ben Jaballah, N., Bouziri, A., Mnif, K., Hamdi, A., Khaldi, A. \& Kchaou, W. (2007). Epidemiology of hospital-acquired bloodstream infections in a Tunisian pediatric intensive care unit: a 2-year prospective study. Am J Infect Control 35, 613-618.

Bisset, L., Cossart, Y. E., Selby, W., West, R., Catterson, D., O'Hara, K. \& Vickery, K. (2006). A prospective study of the efficacy of routine decontamination for gastrointestinal endoscopes and the risk factors for failure. Am J Infect Control 34, 274-280.

Bojer, M. S., Struve, C., Ingmer, H., Hansen, D. S. \& Krogfelt, K. A. (2010). Heat resistance mediated by a new plasmid encoded Clp ATPase, ClpK, as a possible novel mechanism for nosocomial persistence of Klebsiella pneumoniae. PLoS ONE 5, e15467.

Carbonne, A., Thiolet, J., Fournier, S., Fortineau, N., Kassis-Chikhani, N., Boytchev, I., Aggoune, M., Seguier, J., Senechal, H. \& other authors (2010). Control of a multi-hospital outbreak of KPC-producing Klebsiella pneumoniae type 2 in France, September to October 2009. Euro Surveill 15, pii:19734.

Cetre, J. C., Salord, H. \& Vanhems, P. (2003).

Outbreaks of infection associated with bronchoscopes. N Engl J Med 348, 2039-2040.

Chambers, S. T., Peddie, B. \& Pithie, A. (2006). Ethanol disinfection of plastic-adherent microorganisms. J Hosp Infect 63, 193-196.

Costerton, J. W., Cheng, K. J., Geesey, G. G., Ladd, T. I., Nickel, J. C., Dasgupta, M. \& Marrie, T. J. (1987). Bacterial biofilms in nature and disease. Annu Rev Microbiol 41, 435-464.

Couto, R. C., Carvalho, E. A., Pedrosa, T. M., Pedroso, E. R., Neto, M. C. \& Biscione, F. M. (2007). A 10-year prospective surveillance of nosocomial infections in neonatal intensive care units. Am J Infect Control 35, 183-189.

Donlan, R. M. \& Costerton, J. W. (2002).

Biofilms: survival mechanisms of clinically relevant microorganisms. Clin Microbiol Rev 15, 167-193.

Faille, C., Fontaine, F., Lelièvre, C. \& Bénézech, T. (2003). Adhesion of Escherichia coli, Citrobacter freundii and Klebsiella pneumoniae isolated from milk: consequence on the efficiency of sanitation procedures. Water Sci Technol 47, 225-231.

LeChevallier, M. W., Cawthon, C. D. \& Lee, R. G. (1988). Factors promoting survival of bacteria in chlorinated water supplies. Appl Environ Microbiol 54, 649-654.

Mastropierro, R., Bettinzoli, M., Bordonali, T., Patroni, A., Barni, C. \& Manzato, A. (2009).

Pneumonia in a cardiothoracic intensive care unit: incidence and risk factors. J Cardiothorac Vasc Anesth 23, 780-788.

Michalopoulos, A., Falagas, M. E., Karatza, D. C., Alexandropoulou, P., Papadakis, E., Gregorakos, L., Chalevelakis, G. \& Pappas, G.
(2011). Epidemiologic, clinical characteristics, and risk factors for adverse outcome in multiresistant gram-negative primary bacteremia of critically ill patients. Am J Infect Control 39, 396-400.

Montgomerie, J. Z. (1979). Epidemiology of Klebsiella and hospital-associated infections. Rev Infect Dis 1, 736-753.

Naas, T., Cuzon, G., Babics, A., Fortineau, N., Boytchev, I., Gayral, F. \& Nordmann, P. (2010). Endoscopy-associated transmission of carbapenem-resistant Klebsiella pneumoniae producing KPC-2 beta-lactamase. J Antimicrob Chemother 65, 1305-1306.

Pajkos, A., Vickery, K. \& Cossart, Y. (2004). Is biofilm accumulation on endoscope tubing a contributor to the failure of cleaning and decontamination? J Hosp Infect 58, 224-229.

Podschun, R. \& Ullmann, U. (1998). Klebsiella spp. as nosocomial pathogens: epidemiology, taxonomy, typing methods, and pathogenicity factors. Clin Microbiol Rev 11, 589-603.

Sahly, H. \& Podschun, R. (1997). Clinical, bacteriological, and serological aspects of Klebsiella infections and their spondylarthropathic sequelae. Clin Diagn Lab Immunol 4, 393-399.

Sahly, H., Podschun, R. \& Ullmann, U. (2000). Klebsiella infections in the immunocompromised host. Adv Exp Med Biol 479, 237-249.

von Baum, H., Ober, J. F., Wendt, C., Wenzel, R. P. \& Edmond, M. B. (2005). Antibioticresistant bloodstream infections in hospitalized patients: specific risk factors in a high-risk population? Infection 33, 320-326.

Zühlsdorf, B., Winkler, A., Dietze, B., Floss, H. \& Martiny, H. (2003). Gastroscope processing in washer-disinfectors at three different temperatures. J Hosp Infect 55, 276-282. 